\title{
The Effect of the Indium(III) Phthalocyanine Chloride Films on the Behavior of Flexible Devices of Flat and Disperse Heterojunction
}

\author{
María Elena Sánchez-Vergara ${ }^{1, *}$, Raquel Carrera-Téllez ${ }^{1}$, Paulina Smith-Ruiz ${ }^{1}$, Citlalli Rios ${ }^{2}$ \\ and Roberto Salcedo ${ }^{2}$ \\ 1 Engineering Department, Universidad Anáhuac México, Avenida Universidad Anáhuac 46, Col. Lomas \\ Anáhuac, C.P. 52786, Huixquilucan, Estado de México, Mexico; raquecarrera@hotmail.com (R.C.-T.); \\ paau.smith@gmail.com (P.S.-R.) \\ 2 Instituto de Investigaciones en Materiales, Universidad Nacional Autónoma de México, circuito exterior s/n, \\ ciudad universitaria, Coyoacán 04510, Ciudad de México, Mexico; citriogo@yahoo.com.mx (C.R.); \\ salcevitch@gmail.com (R.S.) \\ * Correspondence: elena.sanchez@anahuac.mx; Tel.: +52-555-627-0210 (ext. 8188)
}

Received: 30 August 2019; Accepted: 3 October 2019; Published: 17 October 2019

\begin{abstract}
By means of flat-heterojunction structures based on small semiconductor molecules (MSCs), an analysis of the indium(III) phthalocyanine chloride (In(III) $\mathrm{PcCl}$ ) film as a constituent of optoelectronic devices was performed. The study included the behavior of $\mathrm{In}(\mathrm{III}) \mathrm{PcCl}$ playing three different roles: a donor species, an electronic acceptor, and a hole layer carrier. The flat-heterojunction structures were prepared by vacuum deposition method that permits a controlled layer-by-layer growth of high purity films. The investigated structures were characterized by scanning electron microscopy (SEM), Energy-dispersive X-ray spectroscopy (EDS), UV-vis spectroscopy and optical bandgaps were obtained by Tauc's and Cody's methods. As the structures exhibit a large spectral absorption in the visible range, they were incorporated into flat-heterojunction devices based on flexible and rigid substrates. However, during the synthesis of those structures, the disperse heterojunction arrangement was found and indeed it showed to be more efficient than the initial flat-heterojunction. In order to complement these results, disperse heterojunction arrangement structure as well as its bandgap value were obtained by DFT calculations. Finally, the electronic behavior of both fabricated devices, disperse heterojunction and flat-heterojunction were compared.
\end{abstract}

Keywords: flexible substrate; semiconductor small molecule; DFT calculations; optoelectronic device

\section{Introduction}

The material requirements for the most basic architecture of organic electronic devices include a transparent substrate, a transparent electrode, a light-absorbing organic active layer, and a counter-electrode. Glass is the substrate most frequently employed because it is cheap and it provides a barrier against oxygen and water diffusion into the device [1]. However, the use of flexible substrates, for example polyethylene terephthalate (PET), has been recently considered giving rise to flexible electronics included in new technologies. Devices based on flexible substrates can be ultrathin and comprise the characteristic of adapting to different surfaces. Thus, its development has received much attention and nowadays its assembly can be achieved by vapor-deposition techniques of organic solar cells (OSCs) [2,3]. On the other hand, Forrest et al. has demonstrated that it is also possible the manufacture of organic light emitting diodes (OLED) on polymeric substrates [4]. Furthermore, commercial applications such as optical fibers and optoelectronic devices for the development of flexible flat screens have been found [5-7]. The multiple discovered uses offer 
considerable potential for optoelectronics progress. It is worth mentioning that small semiconductor molecules (MSCs) are a fundamental pillar in the development of flexible electronics, due to their optical and electrical properties and manipulation possibilities [1,8]. MSCs are a class of organic semiconductors and their advantage arises from different characteristics, such as their compatibility with different substrates (including flexible) and the availability of various deposition methods for the preparation of thin films such as spin-coating or high vacuum sublimation. Therefore, the incursion in flexible electronics has promoted the use of MSCs, obtaining a reduction in manufacturing costs and environmental impact. As a consequence, the production of such materials has increase compared to current conventional electronics $[8,9]$. MSCs with intrinsic semiconducting properties were developed in the $60^{\prime}$ s, these attributes are obtained due to their molecular structure and the material selected for its doping $[1,9,10]$. In addition to its semiconductor behavior, MSCs also exhibit optical coupling, which means they are capable of absorbing and emitting light by themselves. These properties provide a wide range of applications in optoelectronic devices. The devices are composed by at least three interfaces: the electrode/donor, donor/acceptor, and acceptor/electrode, where donor and acceptor form the active layer. Depending on the internal structure of their active layer, two main structures are remarkable; the flat heterojunction (FHJ), and the bulk heterojunction (BHJ). In FHJ devices there is a perfectly defined donor/acceptor single interface, conversely, in BHJ the active layer is formed by a mixture of donor and acceptor, which generates a random distribution of these two components. The active layer of the device is responsible for the generation of charge carriers, then the donor and acceptor MSCs that integrate this layer must be chosen in a proper way in order to obtain the highest efficiency in the devices.

The metallophthalocyanines (MPcs) are MSCs widely studied in the manufacture of optoelectronic devices due to their excellent photoactive and photovoltaic properties, in addition to their high thermal and chemical stability. Although over 70 metallic and no metallic ions will fit into the phthalocyanine cavity and many of these MPc complexes have been used in electronic devices, $\mathrm{Cu}$ and $\mathrm{Zn}$ are the most common choices to date to be used in MPc-based electronic devices $[1,11,12]$. The presence of heavy metallic atoms, with valence electrons located in $p$ orbitals as in the case of indium has been little studied and it is worth to consider that depending on the nature of the central metal atom MPc exhibit markedly different device performance [12,13]. The diamagnetic indium(III) metal cation was selected in this study as central metal in phthalocyanine cavity for enhance the optical, photophysical and photochemical properties [13-15]. Additionally the mono-axially chloro substituted indium(III)phthalocyanine is especially known as a promising material for nonlinear optic devices [16-18]. However the chloro indium(III) phthalocyanine seems to be unexplored as a precursor of new materials with semiconductor properties. In the current work, the behavior of indium(III) phthalocyanine chloride $(\mathrm{In}(\mathrm{III}) \mathrm{PcCl})$ in flat-heterojunction structures is studied. The optoelectronic evaluation of the $\mathrm{In}(\mathrm{III}) \mathrm{PcCl}$ film in different flexible devices manufactured over PET is also present. The observed behavior and properties were compared to similar systems deposited over glass. It is worth mention that the study included the behavior of the $\mathrm{In}(\mathrm{III}) \mathrm{PcCl}$ film as donor species, acceptor species and also as a hole transport layer (HTL). The above with the purpose of minimizing the possible loss of current in the devices due to the presence of charge extraction or injection barriers between the electrodes and the phthalocyanine. The behavior of the $\mathrm{In}(\mathrm{III}) \mathrm{PcCl}$ was evaluated through the manufacture and characterization of devices constituted by MSCs widely known for their behavior in optoelectronic devices [1,8-12]. The presence of these MSCs allowed differentiating and determining the behavior of the $\mathrm{In}(\mathrm{III}) \mathrm{PcCl}$, considering also its integration as $\mathrm{FHJ}$ active layer constituent and as $\mathrm{BHJ}$ constituent in devices. The rationale behind this novel idea as contained in this research is based on: (1) the use of heavy indium(III) in the centre of the phthalocyanines and (2) the axial ligation ( $\mathrm{Cl}$ used in this case) minimizes intermolecular interactions which cause aggregation of phthalocyanines $[16,19]$. To the best of our knowledge, the use of $\mathrm{In}(\mathrm{III}) \mathrm{PcCl}$ in flat-heterojunction and disperse-heterojunction flexible structures has not been reported before. Thus, we report for the first time, the use of $\mathrm{In}(\mathrm{III}) \mathrm{PcCl}$ films as donor species, acceptor species and also as HTL. 


\section{Materials and Methods}

\subsection{Characterization of Semiconductors}

The MSCs Indium(III) phthalocyanine chloride (In(III)PcCl: $\mathrm{C}_{32} \mathrm{H}_{16} \mathrm{ClInN}_{8}$ ) with $95 \%$ purity, Poly[2-methoxy-5-(2-ethylhexyloxy)-1,4-phenylenevinylene] (MEH-PPV: $\left.\left(\mathrm{C}_{18} \mathrm{H}_{28} \mathrm{O}_{2}\right)_{n}\right)$ with 99\% purity; Pentacene $\left(\mathrm{C}_{22} \mathrm{H}_{14}\right)$ with $99 \%$ purity; Copper(II) phthalocyanine $\left(\mathrm{Cu}(\mathrm{II}) \mathrm{Pc}: \mathrm{C}_{32} \mathrm{H}_{16} \mathrm{CuN}_{8}\right)$ with 99\% purity; 2,9-Dimethyl-4,7-diphenyl-1,10-phenanthroline (Bathocuproine: $\mathrm{C}_{26} \mathrm{H}_{20} \mathrm{~N}_{2}$ ) with $96 \%$ purity and tetracyano-p-quinodimethane (TCNQ: $\mathrm{C}_{12} \mathrm{H}_{4} \mathrm{~N}_{4}$ ) with $98 \%$ purity were acquired from the commercial supplier Sigma-Aldrich (Saint Louis, MO, USA) and due to their purity certificate, no additional purification was needed. Melting points were obtained from Sigma Aldrich certificates whereas decomposition points were obtained on a Melt-Temp II apparatus (Barnstead Thermolyne Corporation, Dubuque, IA, USA). In order to verify the main functional groups of the MSCs infrared spectroscopy analysis (IR) was performed on a Nicolet iS5-FT spectrometer (Thermo Fisher Scientific Inc., Waltham, MA, USA) on a wavelength of 4000 to $500 \mathrm{~cm}^{-1}$ using $\mathrm{KBr}$ pellets and silicon wafers.

\subsection{Film Deposition and Characterization}

Thin films were deposited on Corning glass slides, indium tin oxide $\left(\mathrm{In}_{2} \mathrm{O}_{3} \cdot\left(\mathrm{SnO}_{2}\right)_{x}\right)$ coated glass slides (glass-ITO) and indium tin oxide coated polyethylene terephthalate film (PET-ITO). To guarantee an accurate performance, all substrates excluding PET-ITO were cleansed under an ultrasonic process using organic solvents (chloroform, methanol and acetone) and dried in vacuum. The MSCs were deposited by sublimation on a vacuum chamber with a molybdenum boat. FHJ structures: (S1) InPcCl/MEH-PPV/CuPc/Bathocuproine, (S2) Pentacene/MEH-PPV/InPcCl/Bathocuproine and (S3) $\mathrm{InPcCl} / \mathrm{TCNQ}$ were manufactured with a layered structure through sequential sublimation depositions using different evaporation ports. On the other hand the active layer for the $\mathrm{BHJ}$ device $(\mathrm{InPCCl}+\mathrm{TCNQ})$, was obtained by a simple reaction in absolute methanol of TCNQ and $\mathrm{In}(\mathrm{III}) \mathrm{PcCl}$ in a conventionally heated reactor Monowave 50 (Anton Paar GmbH, Graz, Austria) with a pressure sensor. The reactor was operated with a borosilicate glass vial and manually closed by a cover with an integrated pressure (0-20 bar) and temperature sensor. The deposition process for the active layer of $\mathrm{BHJ}$ took place using sublimation processes with a tantalum boat. The evaporation rate $(5.2 \AA / \mathrm{s})$, temperature $\left(180^{\circ} \mathrm{C}\right)$ and pressure $\left(1 \times 10^{-5}\right.$ torr $)$ in the vacuum chamber were the same for all the deposition processes. Energy-dispersive X-ray spectroscopy (EDS) and scanning electron microscopy (SEM) were done on a ZEISS EVO LS 10 scanning electron microscope (Carl Zeiss AG, Oberkochen, Germany) with a coupled Bruker microanalysis system (Bruker Nano GmbH, Berlin, Germany). The absorbance of the structures was obtained on a UV-vis 300 Unicam Spectrophotometer (Thermo Fisher Scientific Inc.). Measurements went from the wavelength 200 to $1100 \mathrm{~nm}$ that corresponds to the UV-vis spectrum. In order to determine the optical bandgap with direct and indirect transitions, Tauc and Cody models were used.

\subsection{Device Assembling and Characterization}

The FHJ devices: ITO/InPcCl/MEH-PPV/CuPc/Bathocuproine/Ag (D1), ITO/Pentacene/MEH$\mathrm{PPV} / \mathrm{InPcCl} / \mathrm{Bathocuproine} / \mathrm{Ag} \quad$ (D2), $\quad \mathrm{ITO} / \mathrm{InPcCl} / \mathrm{TCNQ} / \mathrm{Ag} \quad$ (D3) and the $\mathrm{BHJ}$ device $\mathrm{ITO} / \mathrm{InPcCl}+\mathrm{TCNQ} / \mathrm{Ag}$ (D4) were built in PET and glass substrates. The devices are not optimized in terms of the thickness of the films that integrate them. Each layer thickness was monitored through a microbalance quartz crystal monitor connected to a thickness sensor. The thickness of the InPcCl films is $30 \mathrm{~nm}$, the thickness of the MEH-PPV film is $8 \mathrm{~nm}$, the CuPc film is $16 \mathrm{~nm}$ thick while the bathocuproine film is $130 \mathrm{~nm}$ thick. The MEH-PPV polymer was chosen as donor material in D1 and D2 devices, while the MPcs $(\mathrm{M}=\mathrm{In}, \mathrm{Cu})$ were included as electronic acceptor materials. The donor material is the component responsible for the assignment of electrons and is a carrier of holes through its HOMO (Highest Occupied Molecular Orbital), while the acceptor material is the component that receives the electrons and transports them to the cathode through its LUMO 
(Lowest Unoccupied Molecular Orbital). The $\mathrm{InPcCl}$ was also used as the hole transport layer (HTL) in D1, the same as pentacene in D2. Bathocuproine was used as the electrons transport layer (ETL) in D1 and D2 devices. While in D3 and D4 TCNQ was used as acceptor material and InPcCl was chosen as donor material. Table 1 summarizes each type of device with its constituents and the role of each of them. The current-voltage $(I-V)$ measurements were performed employing a programmable voltage source Keithley 4200-SCS-PK1 auto-ranging pico-ammeter (Tektronix Inc., Beaverton, OR, USA). A Next Robotix sensing station with lighting controller circuit (Comercializadora K Mox, S.A. de C.V., Benito Juárez, Distrito Federal, Mexico) acted as a solar simulator that emits electromagnetic radiation between the UV an IR wavelength range. This electrical characterization was carried out through the two-point collinear method.

Table 1. Type of device with their constituents and the function of each one.

\begin{tabular}{|c|c|c|c|c|c|}
\hline Code & $\begin{array}{l}\text { Type of } \\
\text { Device }\end{array}$ & MSC & Structure & Function & $\begin{array}{c}\text { Temperature } \\
\mathrm{mp}\left({ }^{\circ} \mathrm{C}\right)\end{array}$ \\
\hline $\begin{array}{l}\text { D1 } \\
\text { D2 } \\
\text { D3 }\end{array}$ & $\begin{array}{l}\text { FHJ } \\
\text { FHJ } \\
\text { FHJ }\end{array}$ & $\mathrm{In}(\mathrm{III}) \mathrm{PcCl}$ & & $\begin{array}{c}\text { Hole Transport } \\
\text { Layer (HTL) } \\
\text { Electronic } \\
\text { Acceptor } \\
\text { Electronic } \\
\text { Donor }\end{array}$ & $>300$ \\
\hline D1, D2 & FHJ & MEH-PPV & & $\begin{array}{l}\text { Electronic } \\
\text { Donor }\end{array}$ & 190-200 \\
\hline D1 & FHJ & $\mathrm{CuPc}$ & & $\begin{array}{l}\text { Electronic } \\
\text { Acceptor }\end{array}$ & 350 \\
\hline D1, D2 & FHJ & Bathocuproine & & $\begin{array}{c}\text { Electrons } \\
\text { Transport Layer } \\
\text { (ETL) }\end{array}$ & 279 \\
\hline D2 & FHJ & Pentacene & & $\begin{array}{c}\text { Hole Transport } \\
\text { Layer (HTL) }\end{array}$ & 372 \\
\hline D3 & FHJ & TCNQ & & $\begin{array}{l}\text { Electronic } \\
\text { Acceptor }\end{array}$ & 287 \\
\hline D4 & BHJ & $\mathrm{InPcCl}+\mathrm{TCNQ}$ & & Active Layer & $>280$ \\
\hline
\end{tabular}




\subsection{Theoretical Methods}

All calculations were carried out by applying a DFT method based on the combination of Becke's gradient corrections [20] for exchange and Perdew-Wang's for correlation [21]. This is the scheme for the B3PW91 method which is included in Gaussian16 [22] Package. The calculations were performed using the $6-31 \mathrm{G}^{* *}$ basis set. Frequency calculations were carried out at the same level of theory in order to confirm that the optimized structures were at a minimum of the potential surfaces.

\section{Results and Discussion}

The analysis of the $\mathrm{In}(\mathrm{III}) \mathrm{PcCl}$ film as a constituent of optoelectronic devices took place in two parts. (i) During the first part of the study, three FHJ systems, denominated S1, S2 and S3 were manufactured. In those arrangements the $\mathrm{In}(\mathrm{III}) \mathrm{PcCl}$ was studied as hole transporter layer (HTL), as an acceptor and as a donor species respectively. These systems were optoelectronically characterized through the fabrication of the devices D1, D2 and D3. (ii) During the second part of the study, the donor-acceptor species of the active layer with higher optoelectronic properties obtained in the previous stage were analyzed by DFT in order to obtain a BHJ structure more efficient than the FHJ. The chemical composition of BHJ structure is shown in the corresponding scheme in Table 1. The BHJ was assembled experimentally, its bandgap was obtained and compared to the one obtained by DFT. Subsequently, the device D4 was manufactured and finally its electric behavior was compared to its correspondent FHJ device.

\subsection{Manufacture and Characterization of FHJ Structures}

An efficient charge transport inside a device is given when the charges can move from one molecule to another quickly and do not stay trapped or are dispersed. However, the mobility of the charges is affected by some factors such the quality of thin films integrating the device. The study of the morphology of structures is important because it requires the films to be uniform and free of impurities in order to obtain an efficient electric charge transport. To analyze the morphology of the film structures SEM was performed in glass and PET substrates and in Figure 1 it can be observed that the surface morphology is different. As it is shown in Figure 1a, the $\mathbf{S 1}$ (InPcCl/MEH-PPV/CuPc/Bathocuproine) in glass exhibits a homogeneous structure along the entire surface, while in Figure $1 \mathrm{~b}$ particles of different morphology distributed along S2 (Pentacene/MEH-PPV/InPcCl/Bathocuproine) are observed. In this microphotograph elongated particles higher than $1 \mu \mathrm{m}$ and rounded particles lower than $1 \mu \mathrm{m}$ are identified. Apparently, the deposition of the films took place in two stages: initially, the first MSC were deposited directly over the substrate at room temperature, forming the homogeneous layer. In the second stage, the last MSC came in contact to the layer previously deposited, that was above room temperature. Due to the decrease in the thermal gradient during this deposition, additional nuclei slowly grew, forming grains of a considerable size. These results are relevant, because the heterogeneity in the films can affect the charge transportation throughout the sandwich structure. On the other hand, Figure 1d,e show the microphotograph of $\mathbf{S 1}$ and $\mathbf{S} 2$ respectively, deposited on PET. Seemingly the morphology is very dependent on the nature of the substrate: Figure $1 \mathrm{~d}$ for $\mathbf{S 1}$ on PET shows higher size structures with preferential growth directions and marked limits between the areas of preferential growth. Whereas, Figure $1 \mathrm{~b}$ shows that for $\mathbf{S} \mathbf{2}$ structure there is a higher growth of the particles that are in lower amount than those nucleated on glass substrate. It is evident that the glass substrate favors the nucleation of the material, however, as more nuclei is formed, they grow in a smaller size. In contrast, when having PET as a substrate (Figure 1e) the number of nuclei formed is lower and its growth is higher, in addition bigger structures are generated and their growth in preferential directions is favored. Similar results are shown in the microphotography of the $\mathbf{S} 3$ structure: the morphology is different when the films are deposited either over glass or over PET (Figure 1c,f, respectively). In this case, the structure over PET presents a higher homogeneity respect to the structure deposited over glass. 


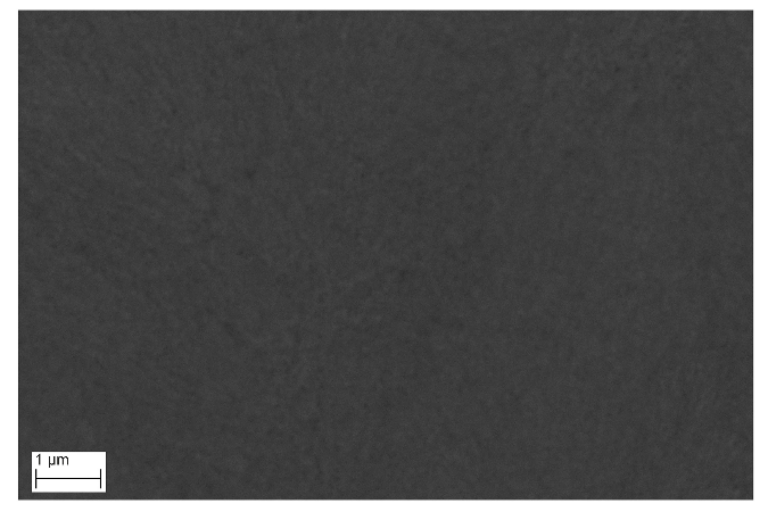

(a)



(C)

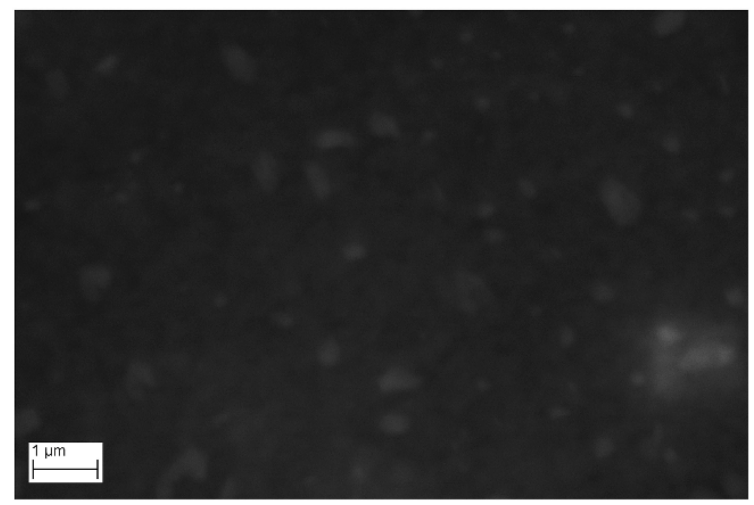

(e)

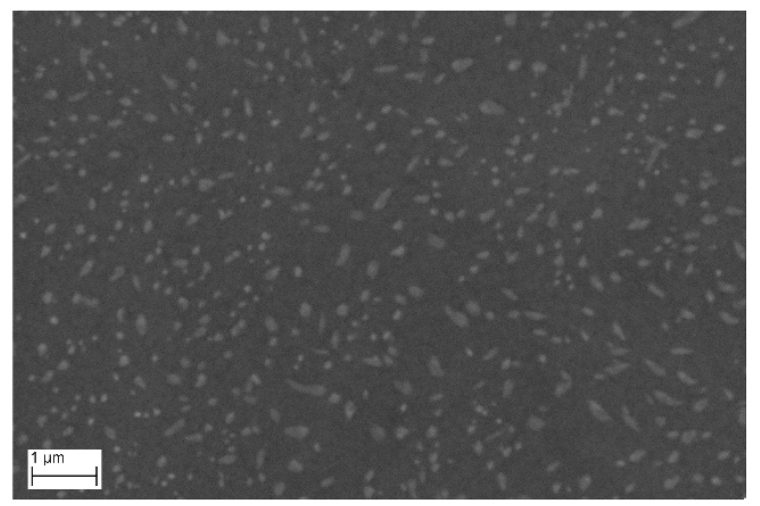

(b)

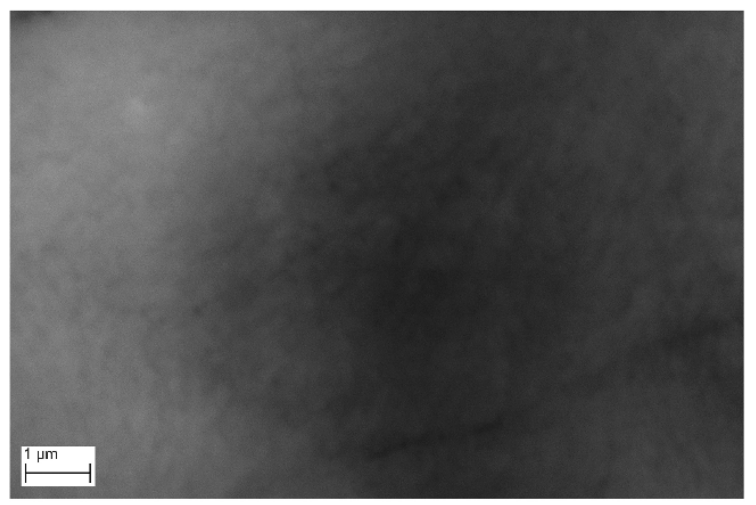

(d)

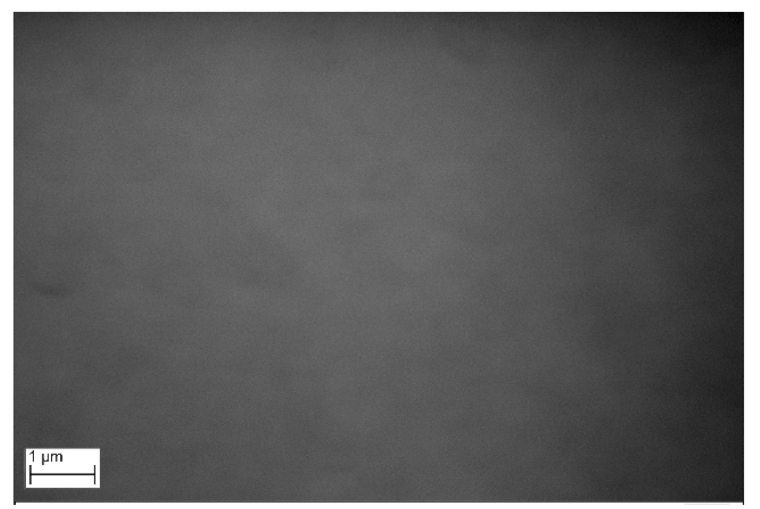

(f)

Figure 1. Microphotograph of (a) S1, (b) S2 and (c) S3 in glass substrate, (d) S1, (e) S2 and (f) S3 in polyethylene terephthalate (PET) substrate at 10000×.

The EDS analysis is important to confirm the presence of the chemical elements that make up the different MSCs in the thin film. The elements present in the MSCs of the S1 are C, N, In, Cl and $\mathrm{Cu}$ (see Table 1). The presence of all the elements was confirmed by the microanalysis performed at $45000 \times$ (Figure 2a). In the S2 and S3 films, the elements C, N, In and Cl were searched and found (see Table 1 and Figure $2 b, c$ ). In both films, there is a predominance of $C$, since it was found in all the MSCs used in the films. The EDS analysis for the systems deposited over PET showed a similar behavior. The results obtained by EDS confirm that high vacuum evaporation is a suitable technique for the manufacture of organic semiconductor films. Apparently, it allows the generation of high purity films, since the deposit is carried out in high vacuum conditions, avoiding the introduction of impurities or polluting substances. The presence of impurities may affect the optoelectronic behavior of systems S1, S2 and S3, because they originate defects in the molecular packing of films [23], causing 
fluctuations at the HOMO and LUMO energy levels of the different type of MSCs that integrate those films.
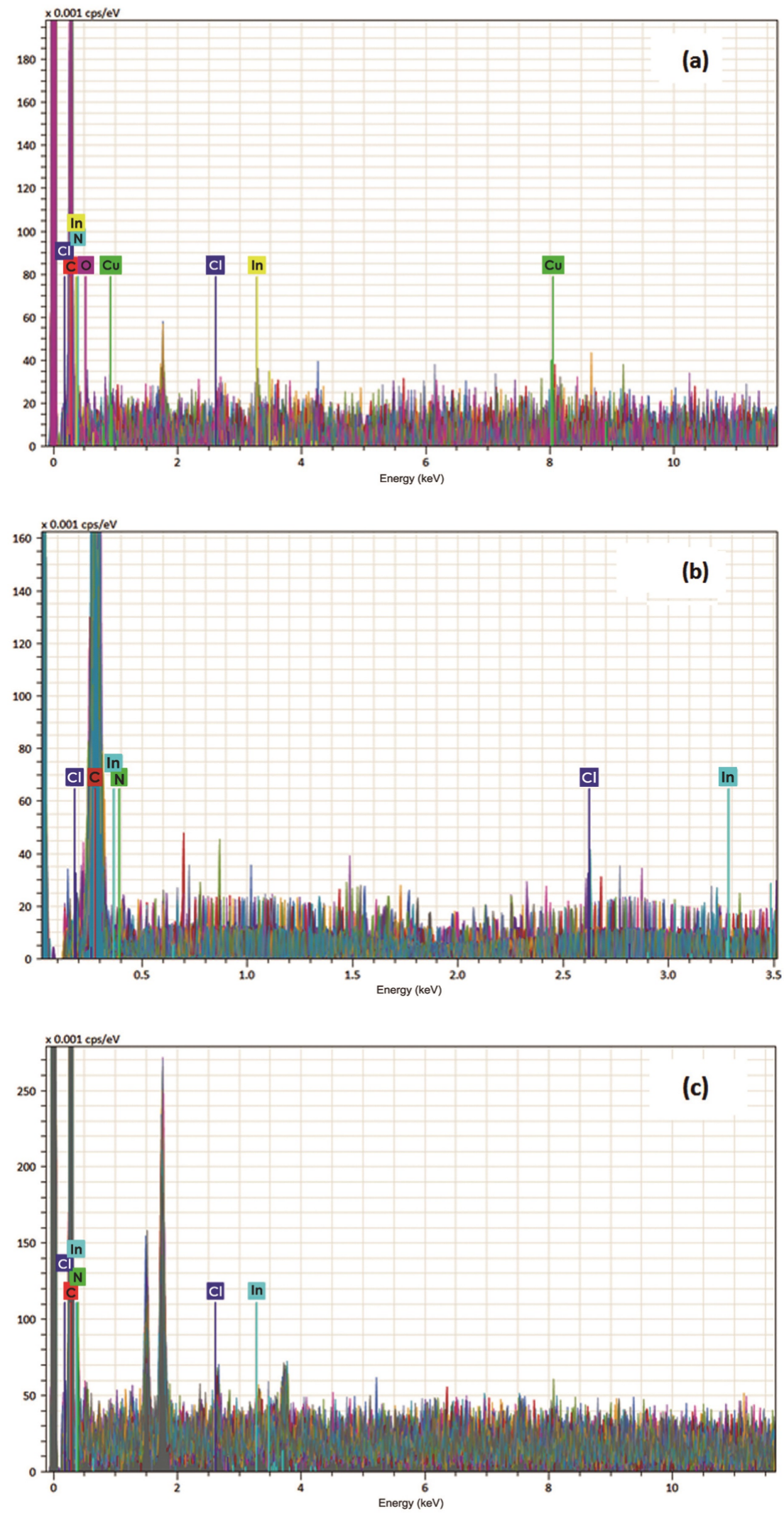

Figure 2. (a) S1, (b) S2 and (c) S3 microanalysis. 
In terms of the absorption properties of the S1, S2 and S3 systems, the UV-vis spectroscopy allowed to analyze the most important electronic transitions of phtalocyanine films. Figure 3 shows the absorption spectra in the wavelength range $200-1100 \mathrm{~nm}$. The spectrum shows the presence of the phtalocyanines: The $B$-band in the near UV region and the $Q$-band on the red side of the spectrum. These bands are related to the molecular orbitals of the aromatic system with $18 \pi$-electrons and to the overlapping orbital on the central metal atom [8]. In Figure 3 a peak is observed in the UV-vis spectra, around $650 \mathrm{~nm}$ for the structures, this corresponds to the $Q$-band of the MPcs, assigned to the first $\pi-\pi^{*}$ transition on the Pc macrocycle [24,25]. The $Q$-band is localized on the Pc ring and is sensitive to the environment of the molecule [26]. Additionally, the $Q$-band in $\mathbf{S 1}$ and S2 structures is split into two peaks and is connected by the $\pi-\pi^{*}$ transition, this band is strongly localized on the phthalocyanine ring [8]. The broadening of the absorption bands can be associated with the aggregation of molecules in thin film [8]. On other hand, the spectra also show that the S1, S2 and S3 systems have the $B$-band around $340 \mathrm{~nm}$ [27]. The electronic $n-\pi^{*}$ transition corresponds to a $B$-band which gives the fundamental absorption edge, this $B$-band corresponds to $a_{2 u}(\pi) \rightarrow e_{g}\left(\pi^{*}\right)$ together with $b_{2 u}(\pi) \rightarrow e_{g}\left(\pi^{*}\right)$ transitions $[27,28]$.

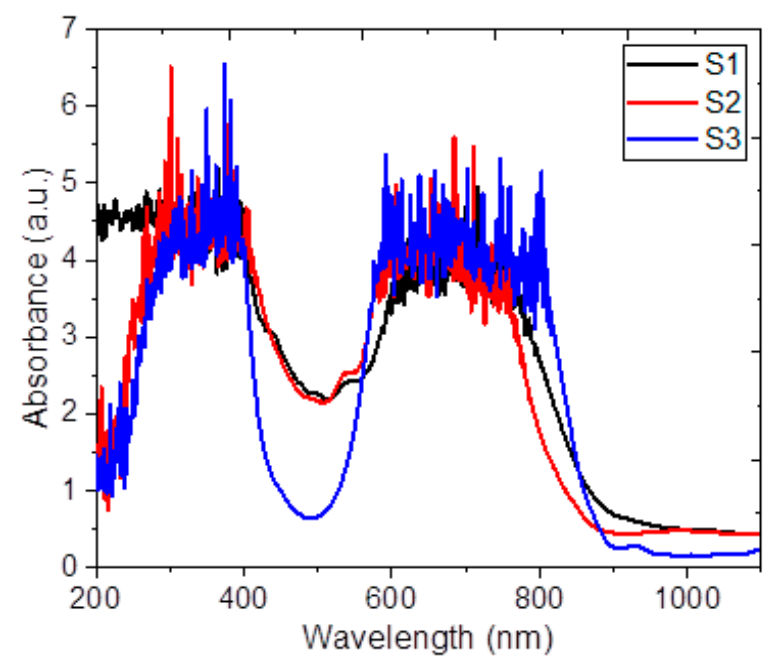

Figure 3. Ultra violet (UV)-vis spectra of S1, S2 and S3.

Optical bandgap is a fundamental parameter to consider in the manufacture of photovoltaic devices in as much as the electronic properties of semiconductors are related to the bandgap. For instance, in photovoltaic devices it controls the efficiency of light absorption. Tauc's model for amorphous semiconductors is one of the most used models for the estimation of the bandgap since it makes it possible to calculate the optical bandgap for direct electronic transitions $(\alpha \mathrm{h} v)^{2}$ as well as indirect electronic transitions $(\alpha \mathrm{h} v)^{1 / 2}[29,30]$. The distinction involves the relative position of the minimum conduction band and the valence band. In a material of direct bandgap, both positions occur in the central zone, during the transition, the electron jumps from the low energy band to the high band by absorbing a photon. In an indirect bandgap material, the conduction band is not in the central zone; instead it is located at the edge area or near to it. Thus, during the transition is not possible to perform the jump between the valence and conduction bands by only absorbing a photon; the transition should involve a phonon to preserve the moment [31]. The obtained optical bandgap values are in Table 2, it is observed that the structures present a bandgap in the range comprised for organic semiconductors [23]. As observed in Table 2, the values of direct bandgap for $\mathbf{S 1}$ and $\mathbf{S 2}$ are practically the same that were calculated for indirect transitions, these results indicate that the charge transport is less dependent of the crystalline or amorphous morphology of the semiconductor film and more dependent of the presence of hole and electron carrier layers in $\mathbf{S 1}$ and $\mathbf{S 2}$ systems. In S3 system, both indirect and direct bandgap transitions are inferior to those obtained for S1 and S2, additionally, in S3 is more evident that the indirect transitions are the dominant, these are characteristics of films with amorphous 
nature. In order to corroborate the obtained bandgap through Tauc's method and to determine the influence of thickness in the bandgap of sandwich structures, an analysis applying the Cody's model Cody et al. [30,32] was included. The model hypothesize that the semiconductor behavior occurs due to a fundamental curvature in the spectral dependence of $(\alpha \mathrm{h} v)^{2}=f(\mathrm{~h} v)$ which they hold responsible for the increases in the Tauc optical gap as associated to thickness [32]. In accordance to Cody's model [30,32], the bandgap associated with the sandwich structures should rather be determined by extrapolating the linear trend observed in the spectral dependence of $(\alpha / \mathrm{h} v)^{2}$, over a range of photon energies. The results for Cody's model are shown in Table 2, it is observed that the obtained bandgap values are slightly higher for direct transitions, while for indirect transitions values for S1 and S2, are similar to that obtained by Tauc's model. These results indicate that the thickness of films does not influence their electric behavior. Whereas for S3, the bandgap of indirect transitions is lower that the obtained by Tauc's model. It is worth to mention that the bandgap obtained for the systems S1, S2 and $\mathbf{S} 3$ exhibits similar values to that of the inorganic semiconductors such as $\mathrm{GaAs}(\sim 1.39 \mathrm{eV})$ or InP $(\sim 1.42 \mathrm{eV})$, besides additional transitions giving indications of the high mobility of electric charges were present.

Table 2. Optic bandgap according Tauc and Cody models.

\begin{tabular}{ccccc}
\hline Sample & $\begin{array}{c}\text { Direct Tauc } \\
\text { Bandgap } \\
(\mathbf{e V})\end{array}$ & $\begin{array}{c}\text { Indirect Tauc } \\
\text { Bandgap } \\
\mathbf{( e V )}\end{array}$ & $\begin{array}{c}\text { Direct Cody } \\
\text { Bandgap } \\
\mathbf{( e V )}\end{array}$ & $\begin{array}{c}\text { Indirect Cody } \\
\text { Bandgap } \\
\mathbf{( e V )}\end{array}$ \\
\hline S1 & 1.37 & 1.36 & 1.43 & 1.34 \\
S2 & 1.37 & 1.37 & 1.49 & 1.36 \\
S3 & 1.34 & 1.25 & 1.42 & 1.14 \\
\hline
\end{tabular}

Based on the previous results, the systems S1, S2 and S3 were incorporated in the devices: glass or PET/ITO/InPcCl/MEH-PPV/CuPc/Bathocuproine/Ag (D1), glass or PET/ITO/Pentacene/MEH-PPV/InPcCl/Bathocuproine/Ag (D2) and glass or PET/ITO/InPcCl/TCNQ/Ag (D3) which are not optimized in terms of the thickness of the films that integrate them. Figure 4 shows the relative distribution of the energy levels correspondent to each one of the MSCs used, since there are few studies performed on optoelectronic devices manufactured from $\mathrm{In}(\mathrm{III}) \mathrm{PcCl}$, theoretical calculations based on the DFT method were carried out in order to obtain the HOMO and LUMO values for the $\mathrm{In}(\mathrm{III}) \mathrm{PcCl}$. Being the obtained values 5.6 and $3.4 \mathrm{eV}$ respectively. Based on the above results, it is proposed that ITO acts as an anode or hole injector, with Fermi level (work function, $\Phi_{\mathrm{f}}=4.8 \mathrm{eV}$ ) near to the energy of HOMO orbitals of organic semiconductor [23]. Whereas silver electrode (Ag), was deposited over the devices acting as cathode or electron injector. The $\Phi_{\mathrm{f}}=4.2 \mathrm{eV}$ of the Ag is close to that of ITO and would provide a field that promotes hole collection at the ITO anode and electron collection at the Ag. According Figure 4a in the device D1, the cathode, with work function of $4.2 \mathrm{eV}$ extracts the electrons coming from the bathocuproine which is the electrons carrier layer. This molecule with its LUMO ( $3.5 \mathrm{eV})$ aligned to the LUMO of the CuPc $(3.5 \mathrm{eV})$ facilitates the electrons transport that the CuPc attracts from donor MEH-PPV. The HOMO of MEH-PPV (5.3 eV) and the $\mathrm{HOMO}$ of $\mathrm{In}(\mathrm{III}) \mathrm{PcCl}(5.6 \mathrm{eV})$ present a suitable energy correspondence, which allows the phthalocyanine to favor the transport to the hole injected by the anode. A similar behavior takes place in D2 device (Figure 4b), however in this case the correspondence between the HOMO of pentacene $(5 \mathrm{eV})$ and the work function of the anode $(4.8 \mathrm{eV})$ is better, thus a more efficient charge transport is expected. With only two layers integrating the device, the D3 case is completely different to the previous (Figure 4c): the $\mathrm{In}(\mathrm{III}) \mathrm{PcCl}$ acts as electronic donor species, and the TCNQ as acceptor. The correspondence between the HOMO of the donor and the work function of the anode is not smaller than in D1 and D2, and the correspondence between the LUMO of the acceptor and the work function of the cathode is maintained with a difference of $0.7 \mathrm{eV}$. Hence, the lowest charge transport is expected in D3, although it is also important to consider that this structure showed the lowest 
bandgap. According to the HOMO and LUMO values for In(III)PcCl obtained by DFT calculations and the relative distribution of HOMO and LUMO energetic levels in $\mathbf{D 2}$, the phthalocyanine would have a better behavior as acceptor species than as hole transporter or electronic donor.

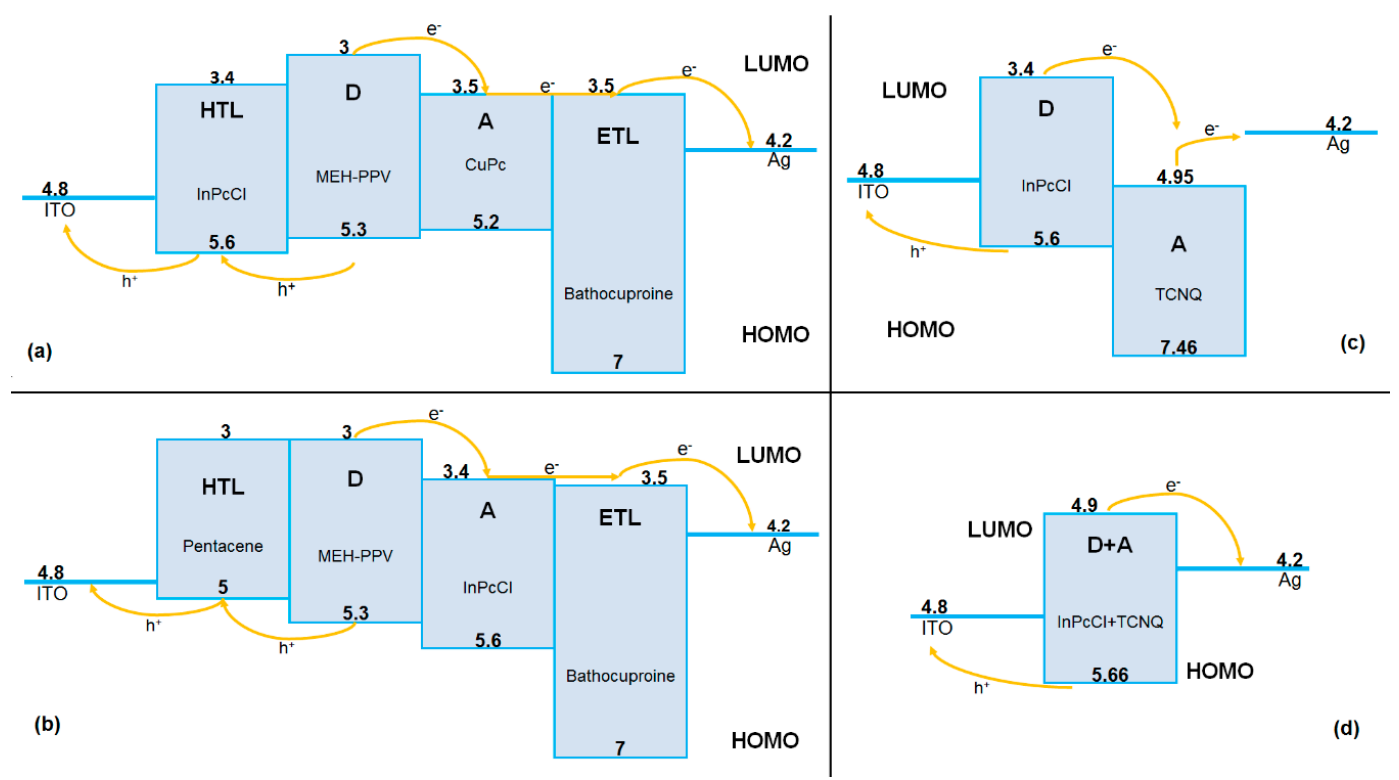

Figure 4. Schematic representation of the relative distribution of Highest Occupied Molecular Orbital (HOMO) and Lowest Unoccupied Molecular Orbital (LUMO) energetic levels in (a) D1, (b) D2, (c) D3 and (d) D4 components.

Electrical properties were determined for the devices (see Figure 5), the measurements were performed under different electromagnetic radiation: (i) darkness conditions where the device would act as a diode. (ii) Natural and artificial white light conditions, which shows how the device would act under solar irradiation [33]. (iii) Red, orange, yellow, green, blue and UV light were also measured in order to determine the individual effect of each of the radiations that constitute the UV-vis spectrum. It is important to mention the difference between white and natural light: the first one uses a white lamp whereas for the second no lamp was needed. Additionally, the evaluation of the electrical behavior was carried out at room temperature. Considering the melting points of the different MSCs used as films in the devices (see Table 1), the thermal stability of the devices is high. This was monitored using IR spectroscopy before and after deposit to the MSCs. From the $I-V$ evaluation, density of current $(J)$ behavior respect to voltage in rigid glass substrates and flexible PET was obtained and is shown in Figure 6. Each graph presents a similar ohmic behavior and it could indicate that the charge injection in the devices is the same, as well as it is also similar the effect of the injection barrier between the thin films and the electrode. However, it is important to notice the effect of the substrate: in Figure $6 \mathrm{a}-\mathrm{c}$ for the devices over glass, is observed that in D1 and D3, the curves obtained in darkness and in presence of UV radiation, show the lowest $J$ values. Otherwise occurs in the device $\mathbf{D 2}$, in which the highest $J$ is obtained in front of UV radiation and in darkness. Additionally, this device transports the highest amount of electric current. Apparently, the $\mathrm{In}(\mathrm{III}) \mathrm{PcCl}$ works properly as electron acceptor, with a difference of $0.1 \mathrm{eV}$ between the value of its LUMO and the LUMO of the bathocuproine. The difference of $0.4 \mathrm{eV}$ with the LUMO of the donor MEH-PPV also favors the electronic transport. Although the behavior on the devices is practically ohmic, the forward voltage at which the current through the junction starts increasing rapidly (cut-in voltage), is around $0.4 \mathrm{~V}$. In the case of devices deposited over PET (Figure 6d-f), variations are more significant. The behavior in D1 (Figure 6d) acquires a direct proportionality between $J-V$, with an increase in more than double the transported current respect to the rest of devices and the highest charge transport is achieved when such device works in nature light conditions. In the device D2 deposited over PET (Figure 6e) the behavior is similar to that 
of the deposited over glass (Figure 6b) although a decrement in its charge transport was observed. Finally, in the device D3 also deposited over PET (Figure 6f), it can be seen a radical change in its behavior: despite the current density is higher than in the device deposited over glass, a less charge saturation occurs and its ohmic behavior is higher. Based on the above, it is evident that the highest current value was registered in the device D1 over PET, such result is an indicative of a more efficient charge injection as a consequence of a higher ohmicity of the contact. The previous results endorse the possibility to include flexible photovoltaics in those devices subjected to high mechanical efforts that could fracture a glass substrate. Whereas the one deposited over PET which showed high elastic module would absorb the charge between its polymer chains. Respect to the behavior of the $\mathrm{In}(\mathrm{III}) \mathrm{PcCl}$ as HTL in the device D1 a proper correspondence between its HOMO at $5.6 \mathrm{eV}$ and the HOMO of MEH-PPV at $5.3 \mathrm{eV}$ is observed. The difference of $0.8 \mathrm{eV}$ respect to the work function of the ITO is lower than the one generated by the pentacene in $\mathbf{D 2}$, which causes a higher current transport in the device D1. In the device D3, there is again a direct contact between $\mathrm{In}(\mathrm{III}) \mathrm{PcCl}$ and ITO (although this time as a donor species) and in the same way as in D1, the current density increases significantly in the device over PET.
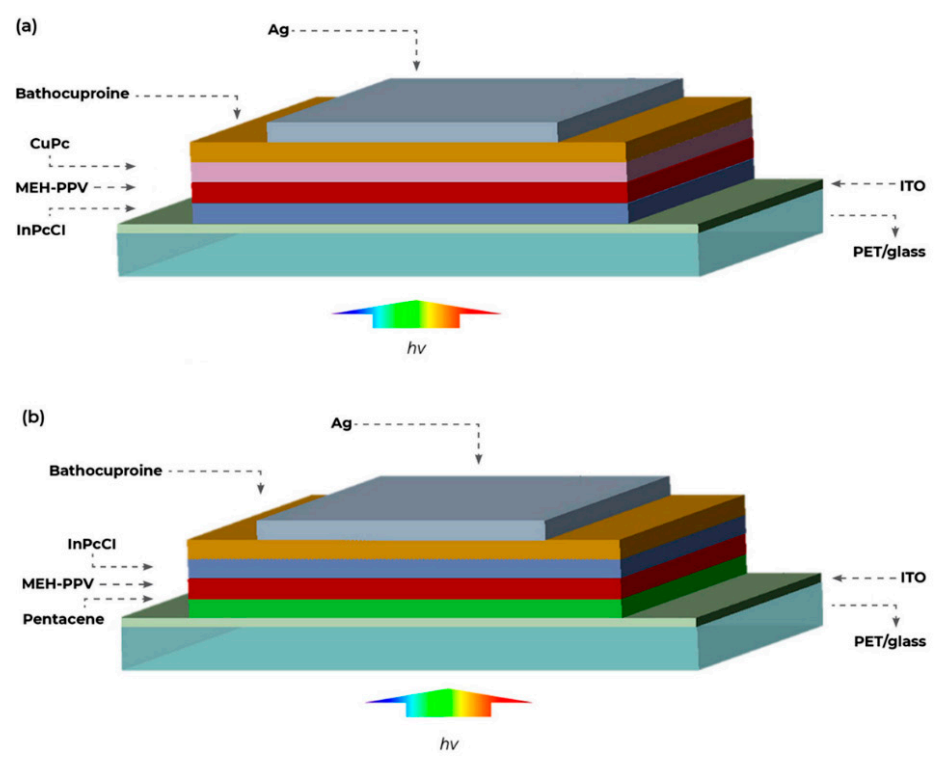

(c)

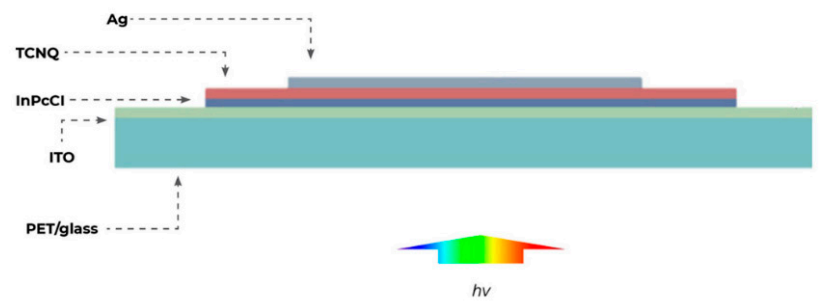

(d)

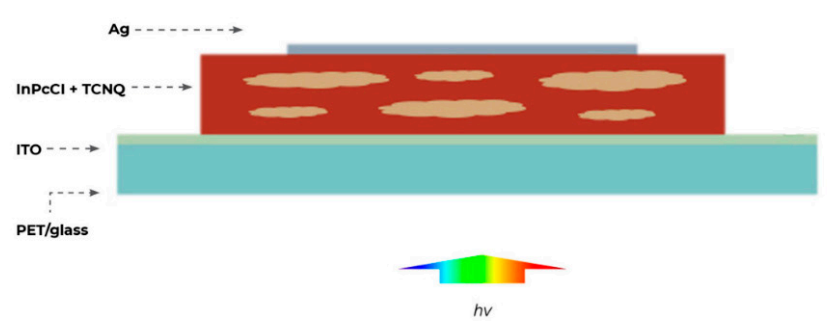

Figure 5. Structure of (a) D1, (b) D2, (c) D3 and (d) D4 devices. 

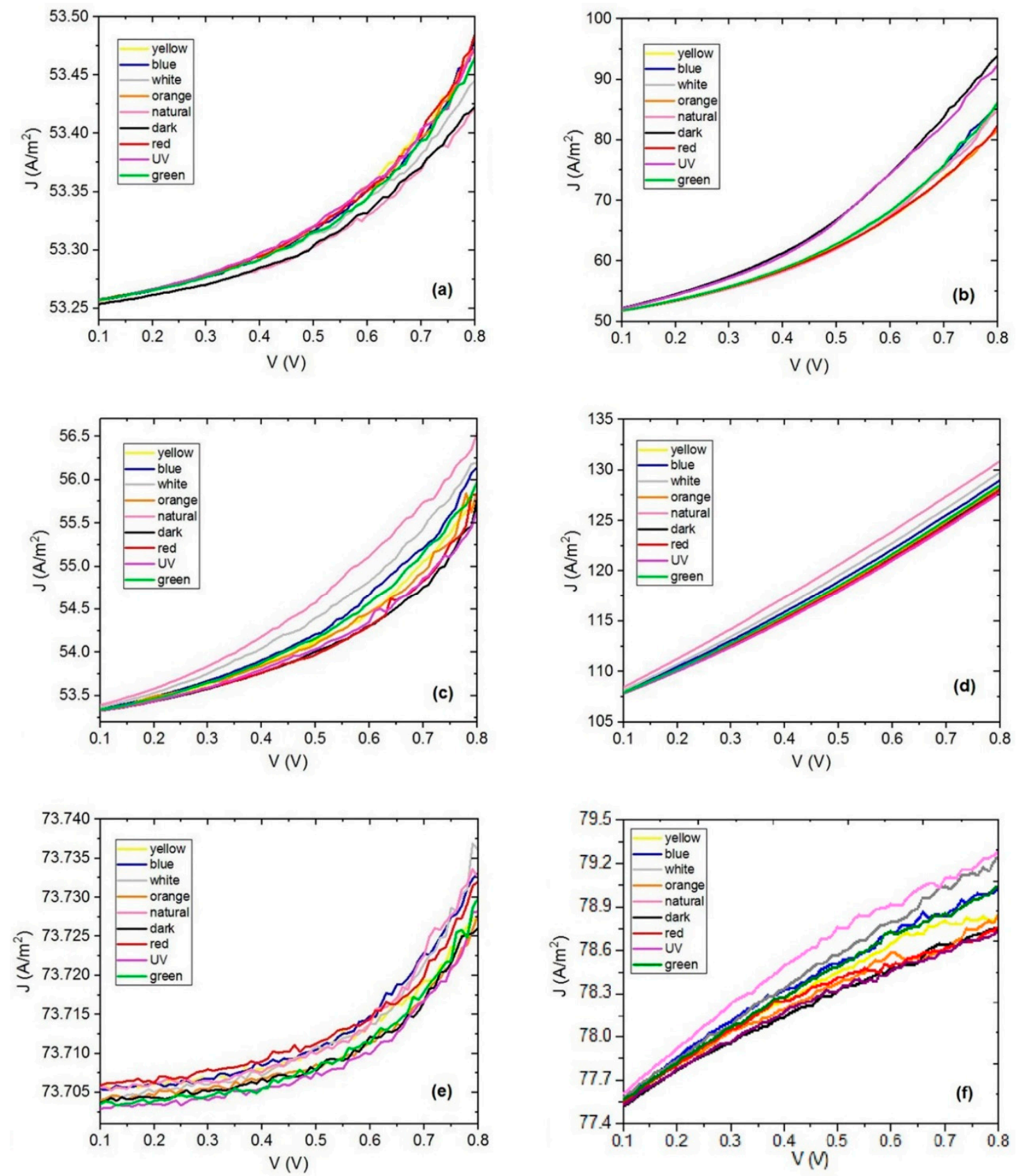

Figure 6. $J-V$ characteristics of (a) D1, (b) D2, (c) D3 in glass and (d) D1, (e) D2, and (f) D3 in PET substrates devices.

\subsection{DFT Calculations and Characterization of BHJ structure}

According to the previous results, the PET/ITO/InPcCl interphases in D1 and D3 are the cause of the increase in the charge transport, regardless the function of the phthalocyanine within the device. In order to verify the above claimed, the chemical structure of the active layer of device D3 was calculated, considering the disperse heterojunction BHJ. The D3 structure was chosen since in this device the $\mathrm{In}(\mathrm{III}) \mathrm{PcCl}$ is part of the active layer as donor species, while in D1 is not part of active layer. DFT calculations were used to obtain the BHJ structure, and also to analyze the molecular orbitals HOMOs and LUMOs, with the corresponding theoretical bandgap. According to the calculations, the TCNQ attacks the indium atom by the trans position to chlorine, with a value of bond energy of $75.93 \mathrm{kcal} / \mathrm{mol}$. It must be considered that this value includes the attack of TCNQ to the indium, as well as the formation of two possible hydrogen bridges (lateral hydrogens of the TCNQ 
with the orbitals of aromatic rings of the phthalocyanine). Figure 7a shows the optimized structure $\mathrm{InPcCl}+\mathrm{TCNQ}$, the distance $a$ corresponds to the hydrogen bridges (average distance $=2.76 \AA$ ) and distance $b$ corresponds to the electrostatic interaction between indium and nitrogen (3.09 $\AA$ ). It is possible to appreciate that it has a pyramidal shape being the indium atom the apex of the pyramid. The TCNQ moiety can interact with the phtalocyanine complex by means two sites. A nitrogen atom from the terminal nitrile group of TCNQ with the free position of indium atom and by two hydrogen bonds which arise from the interaction among the lateral hydrogen atoms of the TCNQ and the carbon atoms of one of the aromatic rings of the phtalocyanine. As can be observed in Figure 7b, the HOMO is over the phthalocyanine and the LUMO is over the TCNQ, the energy values of HOMO and LUMO for $\mathrm{InPcCl}+\mathrm{TCNQ}$ are in Table 3. The theoretical bandgap reported in Table 3 was obtained by calculations for HOMO and LUMO, this value was compared to the Tauc and Cody bandgap values obtained by UV-Vis spectroscopy and reported in the same table. As it was expected, the theoretical bandgap is lower than the experimental due to several factors. First, the experimental value can vary due to film thickness and crystallinity [34]. Furthermore, the comparison between a single molecule (theoretical result) and solid state (experimental result) is expected to involve substantial differences. Additionally, by comparing the experimental bandgap values obtained for structures $\mathrm{FHJ}$ and BHJ, it is observed that the latter are lower. This could be a clue to a better semiconductor behavior in the disperse heterojunction, where there is a continuous phase, and the electrons displace through the $\pi$ bonds of macrocycle and the central metallic atom of the phthalocyanine, to the TCNQ.

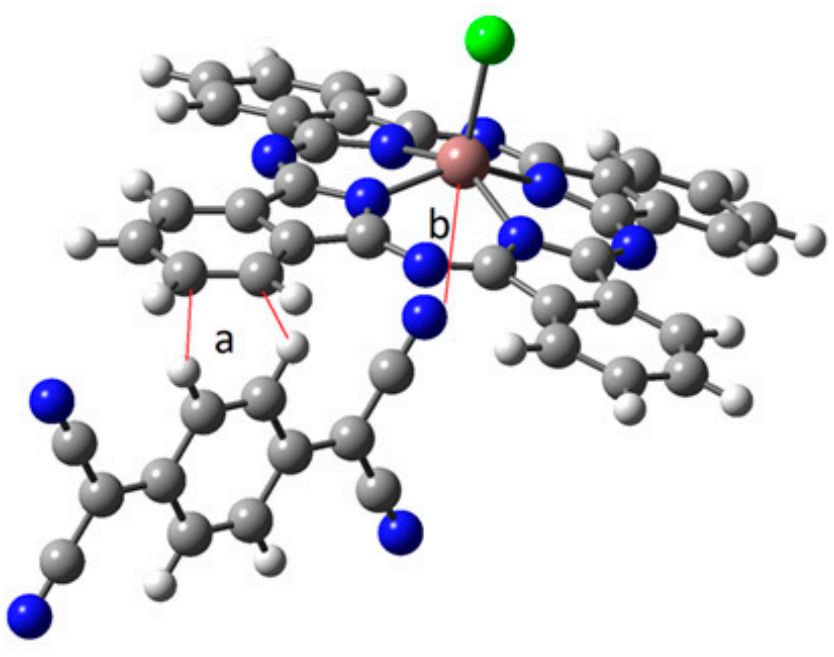

(a)
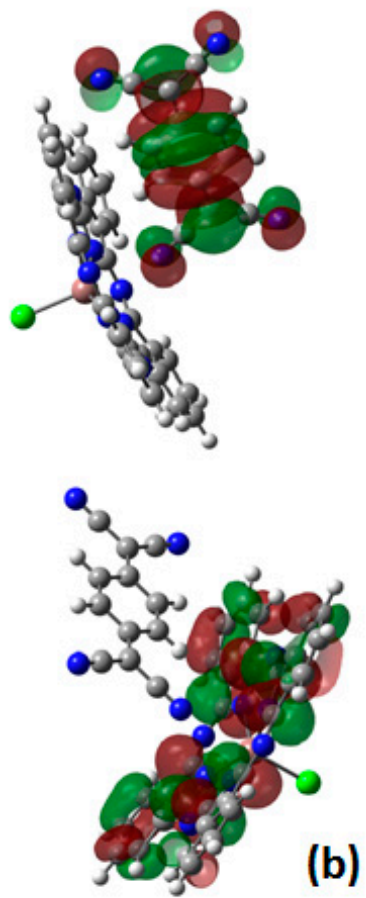

Figure 7. (a) Structure and (b) HOMO-LUMO orbitals for InPcCl + TCNQ.

Table 3. Highest Occupied Molecular Orbital (HOMO) and Lowest Unoccupied Molecular Orbital (LUMO) values and comparison among experimental and theoretical bandgap results of obtained compounds.

\begin{tabular}{cccccccc}
\hline Compound & $\begin{array}{c}\text { HOMO } \\
(\mathrm{eV})\end{array}$ & $\begin{array}{c}\text { LUMO } \\
(\mathbf{e V})\end{array}$ & $\begin{array}{c}\text { DFT } \\
\text { Bandgap } \\
(\mathbf{e V})\end{array}$ & $\begin{array}{c}\text { Direct Tauc } \\
\text { Bandgap } \\
(\mathbf{e V})\end{array}$ & $\begin{array}{c}\text { Indirect Tauc } \\
\text { Bandgap } \\
(\mathbf{e V})\end{array}$ & $\begin{array}{c}\text { Direct Cody } \\
\text { Bandgap } \\
(\mathbf{e V})\end{array}$ & $\begin{array}{c}\text { Indirect Cody } \\
\text { Bandgap } \\
(\mathbf{e V})\end{array}$ \\
\hline $\mathrm{InPCCl}+\mathrm{TCNQ}$ & 5.66 & 4.90 & 0.761 & 1.06 & 1.10 & 1.20 & 1.03 \\
\hline
\end{tabular}

According to the bandgap results, the best semiconductor behavior is obtained with the active layer BHJ. Apparently, the small variation between Tauc bandgap and Cody bandgap indicates that the 
thickness is not a determining factor in the optoelectronic behavior of these structures. But nevertheless; it is necessary to complement the previous information with the evaluation of the electrical behavior of the system with the active layer $\mathrm{BHJ}$. In order to evaluate the electric behavior of the active layer, the glass or PET/ITO/(InPcCl + TCNQ)/Ag (D4) device shown in Figures $4 \mathrm{~d}$ and 5d, was manufactured and its $J-V$ behavior was compared to the one of FHJ device (Figures $4 \mathrm{c}$ and $5 \mathrm{c}$ ). The devices are not standardized; the aim of the study is to analyze the difference in the electric behavior of active layers $\mathrm{FHJ}$ and $\mathrm{BHJ}$. Figure 8 shows the comparison of the $J-V$ study in darkness and natural lighting conditions. The results exhibit an ohmic behavior in the device $\mathbf{D} 4$ with the active layer BHJ. In contrast, although the D3 device with the active layer FHJ generates a higher current density, it suffers a slight electric charge saturation which can be provoked by the interface donor/acceptor. On the other hand, the current density for the device FHJ seems to be lower in darkness than in lighting conditions, which corresponds to a high resistance inside of the device associated to the architecture of the active layer. Respect to the charge transport in darkness and lighting conditions in D4 device a marked difference in the curves is observed, which indicates the possibility they have to be used in photovoltaic applications.
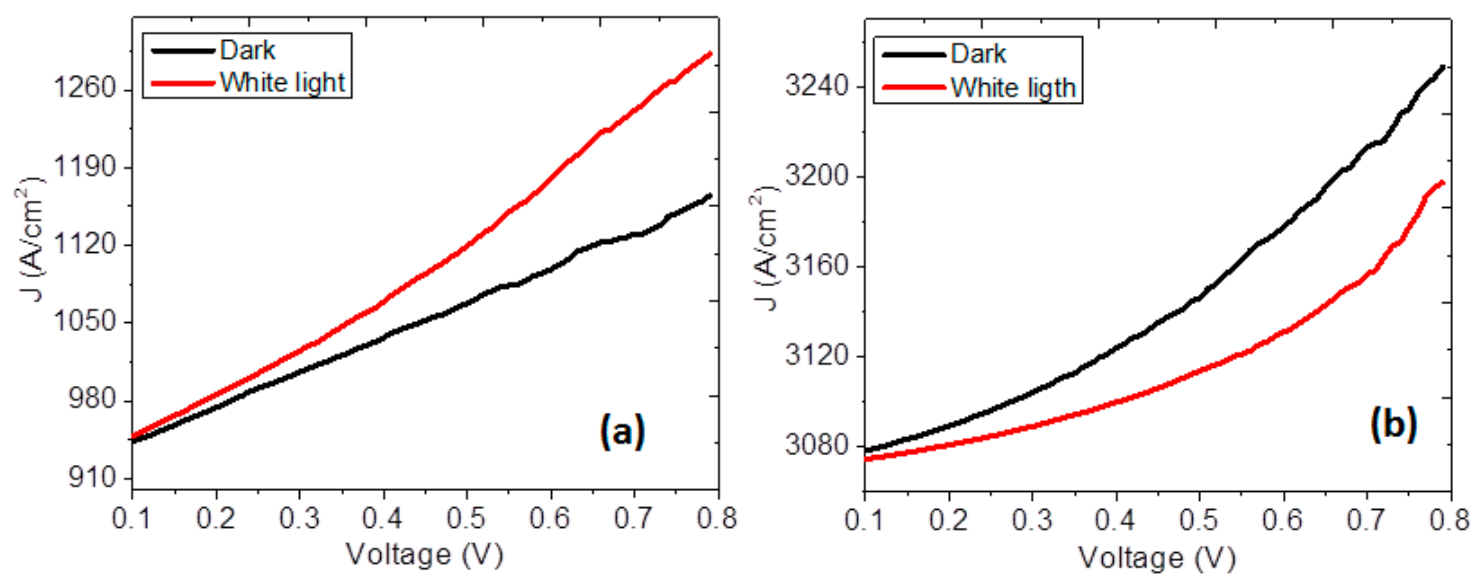

Figure 8. $J-V$ characteristics of the investigated devices D3 and D4 with (a) FHJ and (b) BHJ active layer.

\section{Conclusions}

In order to study the optoelectronic behavior of the $\mathrm{In}(\mathrm{III}) \mathrm{PcCl}$, different type of flat heterojunction systems were fabricated by thermal evaporation and they were studied as three different species: a donor, an acceptor and a hole transporter. Optical bandgaps for the deposited structures were obtained by Tauc's and Cody's methods for both direct and indirect transitions and are between 1.14 and $1.49 \mathrm{eV}$. Four devices were manufactured: glass or PET/ITO/InPcCl/MEH-PPV/CuPc/Bathocuproine/, glass or PET/ITO/Pentacene/MEH-PPV/InPcCl/Bathocuproine/Ag, glass or PET/ITO/InPcCl/TCNQ/Ag and glass or PET/ITO/(InPcCl + TCNQ)/Ag. From $J-V$ study, it was verified that the $\mathrm{In}(\mathrm{III}) \mathrm{PcCl}$ can play donor, acceptor and hole transporter roles depending on the particular experiment. The best results (i.e., the shortest band gaps) were obtained in devices over PET where the $\mathrm{In}(\mathrm{III}) \mathrm{PcCl}$ was in direct contact with the anode as a donor or hole transporter. Additionally, the devices where the phthalocyanine fragment was present as a part of the active layer in the flat heterojunction and in the disperse heterojunction were compared among them and the lowest bandgap (1.03 eV) associated to the best electronic behavior was obtained for the device of disperse heterojunction. The structure of disperse heterojunction was visualized through DFT calculations and according to the results the TCNQ interacts with the indium atom by the trans position to chlorine into the coordination complex (which bears a bond energy of $75.93 \mathrm{kcal} / \mathrm{mol}$ ), besides, two hydrogen bridges are formed for the interaction of both moieties. The HOMO is over the phthalocyanine fragment whereas the LUMO is over the TCNQ one. 
Author Contributions: Conceptualization, M.E.S.-V. and R.C.-T.; Methodology, R.C.-T. and P.S.-R.; Software R.S. and C.R.; Validation, M.E.S.-V., R.C.-T. and P.S.-R.; Formal Analysis, M.E.S.-V.; Investigation, M.E.S.-V., R.C.-T. and P.S.-R.; Resources, P.S.-R..; Data Curation, M.E.S.-V. and P.S.-R.; Writing-Original Draft Preparation, M.E.S.-V., R.S. and C.R.; Writing-Review and Editing, M.E.S.-V., R.S. and C.R.; Visualization, R.C.-T. and P.S.-R.; Supervision, M.E.S.-V.; Project Administration, M.E.S.-V.; Funding Acquisition, M.E.S.-V.

Funding: M. E. Sánchez-Vergara acknowledges the financial support from Anahuac México University, Project number NNAIASEVM16070616.

Acknowledgments: The authors wish to thank the technical assistance of Valeria Martínez Parente-Barrios and Aline Hernandez Garcia. Roberto Salcedo and Citlalli Rios want to thank Teresa Vázquez, Oralia Jimenez, Alberto López, Alejandro Pompa and Cain González for technical help.

Conflicts of Interest: The authors declare no conflict of interest.

\section{References}

1. Hains, A.W.; Liang, Z.; Woodhouse, M.A.; Gregg, B.A. Molecular semiconductors in organic photovoltaic cells. Chem. Rev. 2010, 110, 6689-6735. [CrossRef] [PubMed]

2. Pandey, A.K.; Nunzi, J.M. Efficient flexible and thermally stable pentacene/C60 small molecule based organic solar cells. Appl. Phys. Lett. 2006, 89, 213506. [CrossRef]

3. Kushto, G.P.; Kim, W.; Kafafi, Z.H. Flexible organic photovoltaics using conducting polymer electrodes. Phys. Lett. 2005, 86, 093502. [CrossRef]

4. Gu, G.; Burrows, P.E.; Venkatesh, S.; Forrest, S.R.; Thompson, M.E. Vacuum-deposited, nonpolymeric flexible organic light-emitting devices. Opt. Lett. 1997, 22, 172-174. [CrossRef]

5. Cosseddu, P.; Lai, S.; Barbaro, M.; Bonfiglio, A. Ultra-low voltage, organic thin film transistors fabricated on plastic substrates by a highly reproducible process. Appl. Phys. Lett. 2012, 100, 093305. [CrossRef]

6. Ahn, M.H.; Cho, E.S.; Kwon, S.J. Characteristics of ITO-resistive touch film deposited on a PET substrate by in-line DC magnetron sputtering. Vacuum 2013, 101, 221-227. [CrossRef]

7. Machinaga, H.; Ueda, E.; Mizuike, A.; Takeda, Y.; Shimokita, K.; Miyazaki, T. Effects of annealing temperature on mechanical durability of indium-tin oxide film on polyethylene terephthalate substrate. Thin Solid Film. 2014, 559, 36-39. [CrossRef]

8. Socol, M.; Preda, N.; Rasoga, O.; Breazu, C.; Stavarache, I.; Stanculescu, F.; Socol, G.; Gherendi, F.; Grumezescu, V.; Popescu-Pelin, G.; et al. Flexible heterostructures based on metal phthalocyanines thin films obtained by MAPLE. Appl. Surf. Scien. 2016, 374, 403-410. [CrossRef]

9. Ponce Ortiz, R. Organic Semiconductors based on Oligotiofenos Tetracianosustituidos: Spectroscopic, Electrochemical and Theoretical Study. Ph.D. Thesis, University of Málaga, Málaga, Spain, 2008.

10. Mirsafaei, M.; Fallahpour, A.H.; Lugli, P.; Rubahn, H.G.; Adam, J.; Madsen, M. The influence of electrical effects on device performance of organic solar cells with nano-structured electrodes. Sci. Rep. 2017, 7, 5300. [CrossRef] [PubMed]

11. Zhao, H.; He, Z.; Zhang, X.; Zhang, Z.; Diyaf, Z.; Lind, A.H.N.; Liang, C.; Wilson, J.I.B. A preliminary investigation into hybrid photovoltaic cells with organic phthalocyanines and amorphous silicon heterojunction. J. Phys. D: Appl. Phys. 2015, 48, 19. [CrossRef]

12. Bruder, I.; Schöneboom, J.; Dinnebier, R.; Ojala, A.; Schäfer, S.; Sens, R.; Erk, P.; Weis, J. What determines the performance of metal phthalocyanines ( $\mathrm{MPc}, \mathrm{M}=\mathrm{Zn}, \mathrm{Cu}, \mathrm{Ni}, \mathrm{Fe}$ ) in organic heterojunction solar cells? A combined experimental and theoretical investigation. Org. Elec. 2010, 11, 377-387. [CrossRef]

13. Osifeko, O.L.; Nyokong, T. Effects of symmetry and the number of positive charges on the photocatalytic activity of indium phthalocyanines when embedded in electrospun fibers. Inorg. Chim. Acta 2017, 458, 50-57. [CrossRef]

14. Köksoy, M.A.; Köksoy, B.; Durmus , M.; Bulut, M. Preparation, characterization and photophysicochemical properties of novel tetra 7-(diethyl 2-methylmalonatoxy)-3-(p-oxyphenyl) coumarin-substituted zinc(II) and indium(III)chloride phthalocyanines. J. Organomet. Chem. 2016, 822, 125-134. [CrossRef]

15. Sevim, A.M.; Yenilmez, H.Y.; Aydemir, M.; Koca, A.; Bayır, Z.A. Synthesis, electrochemical and spectroelectrochemical properties of novel phthalocyanine complexes of manganese, titanium and indium. Electrochim. Acta 2014, 137, 602-615. [CrossRef]

16. Özceşmeci, I.; Gelir, A.; Gül, A. Synthesis and photophysical properties of indium(III) phthalocyanine derivatives. J. Lumin. 2014, 147, 141-146. [CrossRef] 
17. Hanack, M.; Dini, D.; Barthel, M.; Vagin, S. Conjugated macrocycles as active materials in nonlinear optical processes: optical limiting effect with phthalocyanines and related compounds. Chem. Rec. 2002, 2, 129-148. [CrossRef]

18. Liu, Y.; Chen, Y.; Cai, L.; Wang, J.; Lin, Y.; Doyle, J.J.; Blau, J.W. Optical limiting properties of axially substituted indium phthalocyanines in the solid PMMA composite films. Mater. Chem. Phys. 2008, 107, 189-192. [CrossRef]

19. Bankole, O.M.; Britton, J.; Nyokong, T. Photophysical and non-linear optical behavior of novel tetra alkynyl terminated indium phthalocyanines: Effects of the carbon chain length. Polyhedron 2015, 88, 73-80. [CrossRef]

20. Becke, A.D. Density-functional exchange-energy approximation with correct asymptotic behavior. Phys. Rev. A 1998, 38, 3098-3100. [CrossRef]

21. Perdew, J.P.; Wang, Y. Accurate and simple analytic representation of the electron-gas correlation energy. Phys. Rev. B 1992, 45, 13244-13249. [CrossRef]

22. Frisch, M.J.; Trucks, G.W.; Schlegel, H.B.; Scuseria, G.E.; Robb, M.A.; Cheeseman, J.R.; Scalmani, G.; Barone, V.; Mennucci, B.; Petersson, G.A.; et al. Gaussian 09, Revision A.01; Gaussian, Inc.: Wallingford, CT, USA, 2009; Available online: https://gaussian.com/g09citation/ (accessed on 6 October 2019).

23. García-Moreno, G. Organic Semiconductors Pi-Conjugated Based in Thiophene, Theoretical Study. Ph.D. Thesis, University of Jaen, Jaén, Spain, 2012.

24. El-Nahass, M.M.; Farag, A.M.; Abd-El-Rahman, K.F.; Darwish, A.A.A. Dispersion studies and electronic transitions in nickel phthalocyanine thin films. Opt. Laser Technol. 2005, 37, 513-523. [CrossRef]

25. El-Nahass, M.M.; Ammar, A.H.; Farag, A.A.M.; Atta, A.A.; El-Zaidia, E.F.M. Effect on heat treatment on morphological, structural and optical properties of CoMTPP thin films. Solid State Sci. 2011, 13, 596-600. [CrossRef]

26. El-Nahass, M.M.; Sallam, M.; Ali, H.A.M. Optical properties of thermally evaporated metal-free phathalocyanine $\left(\mathrm{H}_{2} \mathrm{Pc}\right)$ thin films. Int. J. Mod. Phys. B 2005, 27, 4057-4071. [CrossRef]

27. Regimol, C.C.; Menon, C.S. Effect of annealing and $\gamma$ irradiation on tin phthalocyanine thin films. Mater. Sci. 2007, 25, 649-655.

28. Novotny, M.; Bulir, J.; Bensalah-Ledoux, A.; Guy, S.; Fitl, P.; Vrnata, M.; Lancok, J.; Moine, B. Optical properties of zinc phthalocyanine thin films prepared by pulsed laser deposition. Appl. Phys. A 2014, 117, 377-381. [CrossRef]

29. Tauc, J. Optical properties and electronic structure of amorphous Ge and Si. Mater. Res. Bull. 1968, 3, 37-46. [CrossRef]

30. Mok, T.M.; O'Leary, S.K. The dependence of the Tauc and Cody optical gaps associated with hydrogenated amorphous silicon on the film thickness: $\alpha$ Experimental limitations and the impact of curvature in the Tauc and Cody plots. J. Appl. Phys. 2007, 102, 113525. [CrossRef]

31. Fox, M. Optical Properties of Solids. Ed Oxford University Press. Available online: https://pdfs. semanticscholar.org/23ff/f8d38a2c6566c35950412894bfc6fe5e82e3.pdf (accessed on 6 August 2019).

32. Cody, G.D.; Brooks, B.G.; Abeles, B. Optical absorption above the optical gap of amorphous silicon hydride. Sol. Energy Mater. 1982, 8, 231-240. [CrossRef]

33. Más-Montoya, M. Synthesis of New Heteroacene Systems and Study of Their Properties as Organic Semiconductors for Their Application in Molecular Electronics. Dissertation, University of Murcia, Spain, 2015.

34. Örek, C.; Arslan, F.; Gündüz, B.; Kaygili, O.; Bulut, N. Comparison of experimental photonic and refractive index characteristics of the TBADN films with their theoretical counterparts. Chem. Phys. Lett. 2018, 696, 12-18. [CrossRef]

(C) 2019 by the authors. Licensee MDPI, Basel, Switzerland. This article is an open access article distributed under the terms and conditions of the Creative Commons Attribution (CC BY) license (http://creativecommons.org/licenses/by/4.0/). 